\title{
Community-based clinical education increases motivation of medical students to medicine of remote area -comparison between lecture and practice-
}

\author{
Kenji Tani', Harutaka Yamaguchi', Saaya Tada², Saki Kondo², Ryo Tabata', \\ Shino Yuasa', Shingo Kawaminami', Yoshinori Nakanishi', Jun Ito', \\ Nobuhiko Shimizu', Fumiaki Obata ${ }^{3}$, Teruki Shin ${ }^{4}$, Hiroyasu Bando ${ }^{3}$, and \\ Mitsuhiro Kohno' \\ ${ }^{1}$ Department of General Medicine, Institute of Health Biosciences, the University of Tokushima Gradu- \\ ate School, Tokushima, Japan ; ${ }^{2}$ Third year student, the University of Tokushima Faculty of Medicine, \\ Tokushima, Japan ; ${ }^{3}$ Kaifu Tokushima Prefectural Hospital, Tokushima, Japan $;{ }^{4}$ Hyogo Prefectural \\ Kaibara Hospital, Hyogo, Japan
}

\begin{abstract}
In this study, we administered a questionnaire to medical students to evaluate the effect of community-based clinical education on their attitudes to community medicine and medicine in remote area. Questionnaires were given 4 times to all the students from first-year to sixth-year. Of 95 students, 65 students (68.4\%) who completed all questionnaires, were used in this study. The intensity of students' attitudes was estimated by using visual analogue scale. The intensity of interest, a sense of fulfillment and passion in medicine of remote area was significantly increased after the community-based practice. On the other hand, the level of understanding in medicine in remote area was increased by the lecture not by the practice. The intensity of desire both to become a generalist and a specialist was significantly increased when the grade went up. Most of sixth-year students desired to have abilities of a generalist and a specialist simultaneously. This study shows that the community-based practice is more meaningful in increasing motivation in medicine in remote area than the lecture, and suggests that it is important to prepare more courses to experience community medicine to increase the number of physicians who desire to work in remote area. J. Med. Invest. 61 : 156-161, February, 2014
\end{abstract}

Keywords : community-based practice, remote medicine, generalist, clinical clerkship

\section{INTRODUCTION}

Community-based medical education has been introduced in many medical schools in Japan $(1,2)$.

Received for publication December 2, 2013 ; accepted January $10,2014$.

Address correspondence and reprint requests to Kenji Tani, M.D., Department of General Medicine, Institute of Health Biosciences, the University of Tokushima Graduate School, 18-15 Kuramoto-cho 3, Tokushima 770-8503, Japan and Fax : +81-88633-9687.
It is important in increasing general medicine faculties, and provides medical students with opportunities to learn basic information about environments, health service and development of the community, and to experience an importance of interaction with people from a wide range of social and cultural backgrounds, which are difficult to learn in the university hospital (3).

The lecture about community medicine, which started in Tokushima University in Jan, 2008, has 
been performed at the lecture room in the university for all medical students. A clinical clerkship practice to experience community medicine to all medical students was introduced in our University in Jul, 2008 (4). Before starting the practice, we selected communities and facilities that provide appropriate learning environments for students, and performed orientations to inform them the purpose of students' visit. Students have rounded a variety of hospitals, clinics and welfare facilities in the remote area, and have learned the importance of general medicine in community medicine. A visiting home care and health education for residents have been included in the schedule. These experiences are considered to be difficult to have in the clinical clerkship of the university hospital (5). Students should know what to do in the community, being aware that community members including nurses, public health nurses and care managers can be important teachers and active partners in the community activities.

The lecture can inform students the knowledge of medical systems such as medical insurance, nursing care system and the role of hospitals and clinics. On the other hand, the practice is useful to experience problems and measures of community medicine including a shortage of doctors in remote area (5-8). In this study, we administered a questionnaire to medical students to evaluate the effect of community-based clinical education on their attitudes to community medicine and medicine in remote area.

\section{MATERIALS AND METHODS}

This investigation conformed to the principles outlines in the Declaration of Helsinki. A same questionnaire was given 4 times to all students at firstyear, third-year, fifth-year and sixth-year. Of 95 students, 65 students (68.4\%) who completed the 4 times questionnaires were used in this study. Table 1 shows a list of questionnaire entries which consists of 9 questions. In this study, community medicine is defined as medical treatment and health care program performed in the limited area, and when the community medicine is performed in rural area it is called medicine in remote area. The intensity of students' attitudes was estimated in each student by using visual analogue scale (VAS) (4). VAS is a simple method to obtain a self-rating. It is a horizontal $100 \mathrm{~mm}$ VAS, with endpoints of 100 (strongest state) at the right and 0 (weakest state) at the left.
Table 1. Questionnaire entries

Q1) Are you interested in community medicine?

Q2) Are you interested in medicine in remote area?

Q3) Do you feel a sense of fulfillment working in community medicine?

Q4) Do you feel a sense of fulfillment working in medicine in remote area?

Q5) Do you understand community medicine?

Q6) Do you understand medicine in remote area?

Q7) Do you want to work in medicine in remote area?

Q8) Do you want to become a generalist in the future?

Q9) Do you want to become a specialist in the future?

The lecture in the community-based medical education was performed for all students in third-year and fourth-year, for 3 and 5 hours, respectively. The community-based practice was performed in the education of clinical clerkship for all medical students from July in fifth-year to June in sixth-year. They stayed in Kaifu county which is placed at remote area in south of Tokushima Prefecture during one week, and visited various medical facilities to learn medicine and welfare, health care, nursing care, and team work with medical staffs in the community medicine. Results of first-year students showed their attitudes just after entering the university ; those of third-year students did just before the lecture ; those of fifth-year students did after the lecture and just before the practice ; and those of sixth-year students did just after the practice. From the results of questionnaires, we analyzed the difference in students' attitudes between pre- and postlecture and between pre- and post-practice.

\section{Statistical analysis}

Differences in measured variables were analyzed with the Wilcoxon signed-rank test. The results were regarded as significant when $\mathrm{p}$ value was $<0.0083$. All statistical analyses were performed using IBM SPSS statistics version 21 software.

\section{RESULTS}

Results of students' attitudes by a questionnaire are shown in Fig. 1. As shown in Fig. 1A, the intensity of interest in medicine in remote area was generally lower than that of community medicine. There is no significant difference in the intensity of interest in community medicine among first-year, third-year and fifth-year students, but a significant increase was observed in sixth-year students. Significantly 
decreased level of interest in medicine in remote area was detected in third-year students when compared with first-year students. The intensity of interest in medicine in remote area was increased in fifth-year students to the level equal to that in firstyear students, and increased in sixth-year students significantly more than in first-year students.

The intensity of a sense of fulfillment was significantly increased in sixth-year students when compared with first-year, third-year and fifth-year students in both community medicine and medicine in remote area (Fig. 1B). On the other hand, the intensity of understanding was significantly increased in fifth-year students when compared with first-year and third-year students in both community medicine and medicine in remote area, and the increased level maintained to sixth-year (Fig. 1C). The intensity of passion for working in remote area in the future was significantly decreased in third-year students when compared with first-year students. It

\section{A) Interest}

Q1) Community medicine

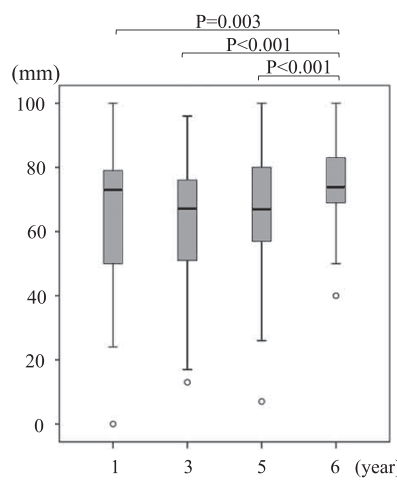

C) Understanding

Q5) Community medicine
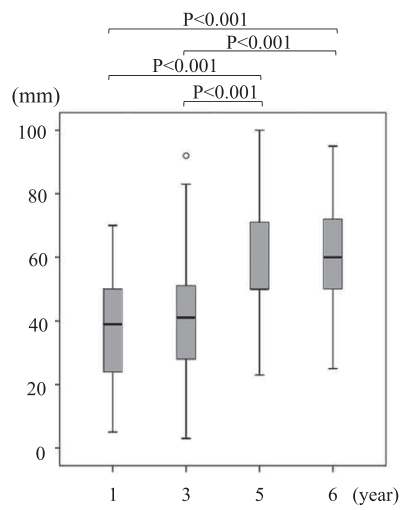

E) Future design

Q8) Generalist

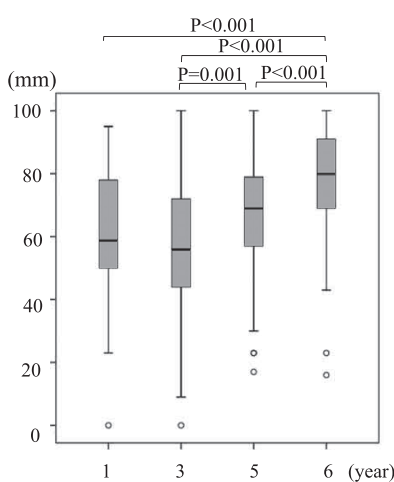

Q2) Medicine in remote area

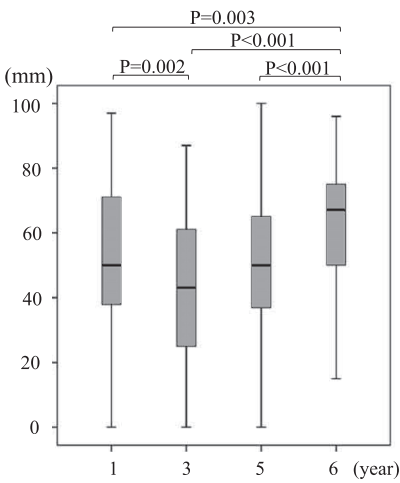

Q6) Medicine in remote area

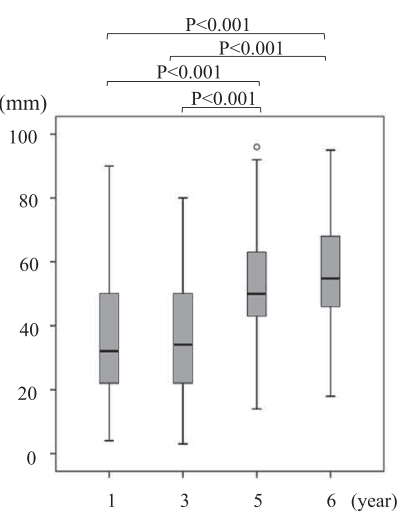

Q9) Specialis

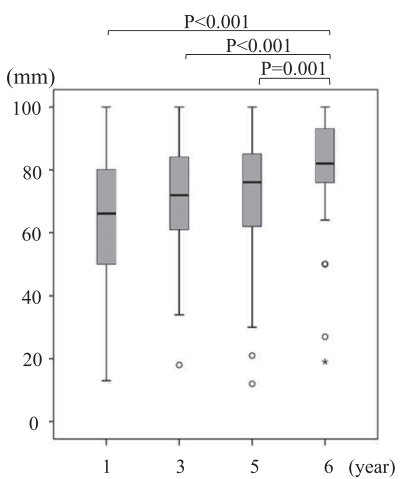

B) A sense of fulfillment

Q3) Community medicine

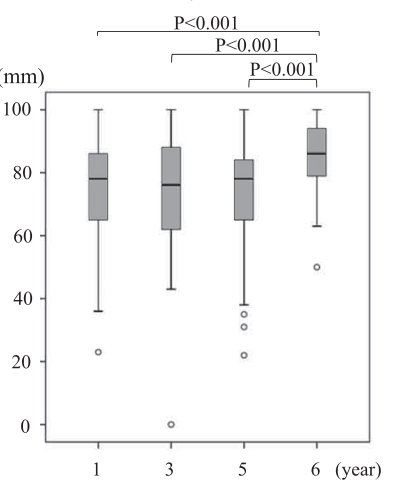

Q4) Medicine in remote area

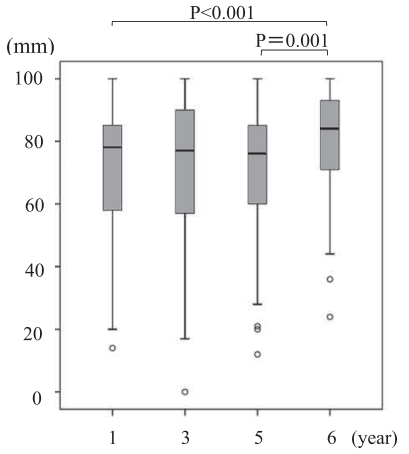

D) Passion

Q7) To work in remote area

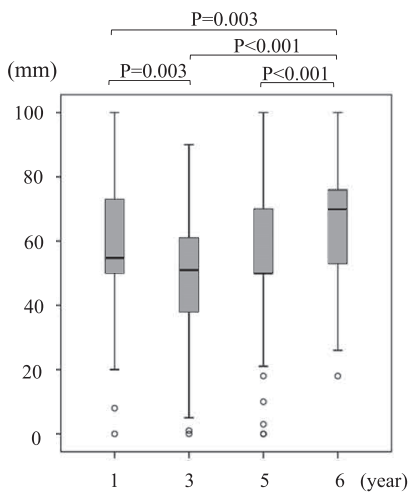

Figure 1 A questionnaire shown in Table 1 was administered for medical students, and the intensity was estimated in each student by using visual analogue scale (VAS). Data are presented as box plots, where the boxes represent the $25^{\text {th }}$ to $75^{\text {th }}$ percentiles, the lines within the boxes represent the median, and the lines outside the boxes represent the last data point that occurs below the $25^{\text {th }}$ or above the $75^{\text {th }}$ percentile and their respective inner fence (1.5 times the interquartile distance). 
was increased in fifth-year students to the level equal to first-year students and increased in sixthyear students significantly more than in first-year students (Fig. 1D). The intensity of desire to become a generalist in the future was increased as a grade went up (Fig. 1E). The intensity of desire to become a specialist was significantly increased in sixth-year students when compared in first-year, third-year and fifth-year students.

The VAS intensity of desire to become a generalist and a specialist was divided into 2 levels ; data of $75 \mathrm{~mm}$ or more were classified as High, and data less than $75 \mathrm{~mm}$ as Low. According to this division, students were divided into 4 groups : group $\mathrm{H}$; High level for both a generalist and a specialist, group $\mathrm{G}$; High level for a generalist and Low level for a specialist, group S ; Low level for a generalist and High level for a specialist, and group L : Low level for both a generalist and a specialist. As shown in Table 2, the number of students in group $G(n=15)$ was almost equal to that in group $S(n=16)$ in first-year students. When a grade went up to sixth-year, the number of students in group $\mathrm{G}$ was decreased to 6 but that of them in group $\mathrm{S}$ did not change. The number of students in group $\mathrm{H}$ was much more in six-year students than in first-year students. On the other hand, the number of students in group $L$ was much few in sixth-year students than in first-year students. Figure 2 shows changes of desire to become a generalist and a specialist when a grade went up from first-year to sixth-year. When a grade went up to sixth-year, movements of students between group $\mathrm{G}$ and group S were observed. Most of students in group $\mathrm{G}$, group $\mathrm{S}$ and group $\mathrm{L}$ in firstyear changed to group $\mathrm{H}$ in sixth-year, and students in group $\mathrm{S}$ in sixth-year were mainly from group $\mathrm{G}$ and group $\mathrm{L}$.

Table 2. Comparison of desire to become a generalist and a specialist between first-year and sixth-year students. The VAS intensity of desire to become a generalist and a specialist was divided into 2 levels ; data of $75 \mathrm{~mm}$ or more are classified as High, and data less than $75 \mathrm{~mm}$ into Low. According to this division, students are divided into 4 groups ; group $\mathrm{H}$; high level for both a generalist and a specialist, group $\mathrm{G}$; high level for a generalist and low level for a specialist, group $\mathrm{S}$; low level for a generalist and high level for a specialist, and group L ; low level for both a generalist and a specialist.

First-year
\begin{tabular}{|c|c|c|c|c|c|}
\hline Group & H & G & S & L & \multirow{2}{*}{ Total } \\
Generalist & High & High & Low & Low & \\
\hline Specialist & High & Low & High & Low & \\
\hline n & 9 & 15 & 16 & 25 & 65 \\
\hline$\%$ & 13.8 & 23.1 & 24.6 & 38.5 & 100 \\
\hline
\end{tabular}

Sixth-year
\begin{tabular}{|c|c|c|c|c|c|}
\hline Group & H & G & S & L & \multirow{2}{*}{ Total } \\
Generalist & High & High & Low & Low & \\
\hline Specialist & High & Low & High & Low & \\
\hline $\mathrm{n}$ & 36 & 6 & 16 & 7 & 65 \\
\hline$\%$ & 55.4 & 9.2 & 24.6 & 10.8 & 100 \\
\hline
\end{tabular}

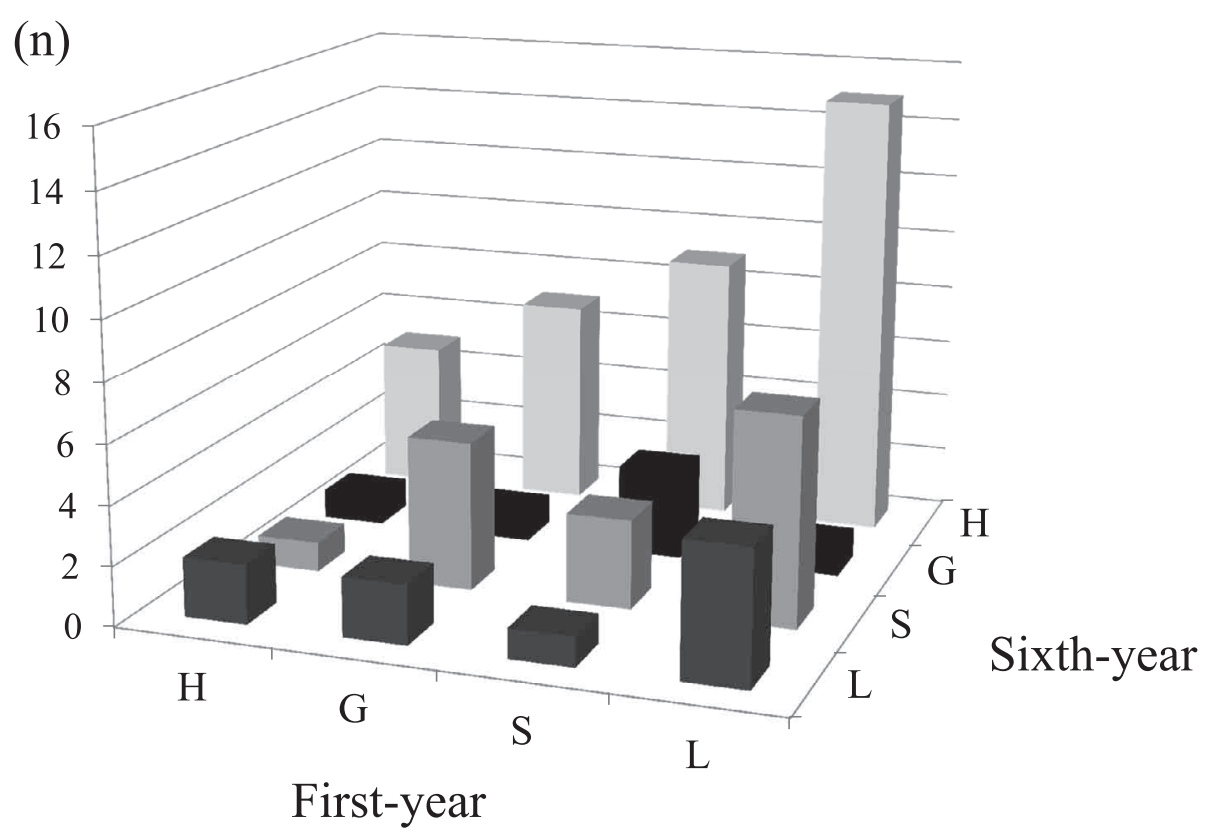

Figure 2 Changes of desire to become a generalist and a specialist from first-year to sixth-year. Students were divided into 4 groups : group $\mathrm{H}$; high level for both a generalist and a specialist, group $\mathrm{G}$; high level for a generalist and low level for a specialist, group S ; low level for a generalist and high level for a specialist, and group $\mathrm{L}$; low level for both a generalist and a specialist. 


\section{DISCUSSION}

This study clarified that the intensity of students' attitudes about interest and a sense of fulfillment in community medicine and medicine of remote area was significantly increased after the communitybased practice. The intensity of passion to work in remote area was also greatly increased after the practice. On the other hand, the lecture showed only small effect on increasing motivation to work there though it increased the level of understanding of both community medicine and medicine in remote area. These results indicated that the practice is more meaningful in increasing motivation for medicine in remote area than the lecture. Previous reports showed the importance of an early primary care experience for medical students $(9,10)$. Therefore, repeated community-based practices as the early exposure education may be important to increase and maintain motivation for medicine of remote area. One of aims of community-based education is to prepare medical students for future professional work in community medicine $(11,12)$. There is a community medicine research club which was formed by medical students in Tokushima University on Oct, 2009 (4). It has 144 members on Oct, 2013. They have visited various medical facilities to learn community medicine and welfare, health care, nursing care and team work with medical staffs. Since this club consists of students from first-year to sixth-year, its activities may be useful to give the students chances to raise and maintain motivation for community medicine and medicine in remote area. It is also important to prepare clinical courses to train general medicine in post-graduated practice system to make motivation of the students realized.

This study showed that the intensity of both interest and passion to work in remote area was relatively high in first-year students but significantly decreased in third-year students. This decrease was seen only in third-year students not in fifth-year or sixth-year students. Although the reason of a temporary decrease in the motivation for medicine in remote area is unknown, it is suggested that the education in the university about advanced lectures for basic clinical competence may result in the decrease of motivation to work in remote area. Early exposure educations for medicine of remote area may be important to maintain the motivation. Further study is needed to clarify factors to affect the intensity of students' motivation for medicine of remote area.
After the community-based education, the intensity of desire to become a generalist was increased. The intensity of desire to become a specialist was also increased as a grade went up. Therefore, we investigated how the desire to become a generalist and a specialist changed in each student when a grade goes up. When a grade went up to sixth-year, movements of students between generalist-predominant group (group G) and specialist-predominant group (group S) were observed. Interestingly, students who desire to become a generalist and a specialist simultaneously (group H) were greatly increased when a grade went up, and $55.4 \%$ of sixthyear students were in group $\mathrm{H}$, indicating that most of students just before graduation desire to have abilities of both a generalist and a specialist. On the other hand, there was a group who showed negative desire for both a generalist and a specialist (group L) though the number of the students was much decreased when a grade went up from first-year to sixth-year. We may need to take care of these students carefully because they may lose desire to become a clinical doctor. Since various factors except education may affect their future design as becoming a generalist and a specialist, further studies are needed to clarify the effect of community-based education on students' desire for a generalist.

This study showed that the community-based practice increased motivation of medical students for medicine in remote area which may result in increasing the number of generalists who work there. The necessity for generalists has been increasing in Japan by the following two reasons. First, a severe aging society is on progress in Japan. The population of aged people is estimated to be increasing, and people aged 75 or over will occupy approximately $20 \%$ in 2030 (13). Since aged people have various complicated diseases, they need generalists who can care a variety of diseases. Second, the shortage of medical doctors is now a serious social problem in community medicine of Japan. Japan has fewer physicians per residents than most other OECD countries (14). Therefore, the Ministry of Health and Labor has increased the number of medical students into the university since 2009 (15). Moreover, the number of doctors distributes more in urban area than in remote area, resulting in an uneven distribution in each prefecture (16). Generalists are needed in community medicine especially in remote area where physicians are insufficient. This study indicates that community-based medical education is a key component in increasing the 
number of generalists who can contribute to medicines in remote area.

Results of this study were possible to be biased by the selection of students because data from only 65 students (68.4\%) who completed all questionnaires were used resulting in removal of students with poor percentage of attendance for the lecture. Moreover, various activities except the lecture and the community-based practice such as the community medicine research club described above as an early exposure may affect an increase in motivation of students to medicine of remote area.

In conclusion, this study showed that communitybased practice motivates students to work in medicine in remote area. The program of practice needs to be evaluated from the students' viewpoint and to be improved, and it is important to prepare more courses to learn community medicine as the early exposure education to increase the number of physicians who want to work in remote area.

\section{CONFLICT OF INTEREST}

None of the authors have any conflicts of interest to declare.

\section{ACKNOWLEDGEMENTS}

The authors thank Ms. Yayoi Tagawa for her valuable secretarial support.

\section{REFERENCES}

1. Kozu T: Medical education in Japan. Acad Med $81:$ 1069-1075, 2006

2. Takayahiki A, Okayama M, Mise J, Ohtaki J, Nakamura Y, Kajii E : National survey of primary care curricula for undergraduate medical students in Japan. 34 : 215-222, 2003

3. Dornan T, Littlewood S, Margolis SA, Scherpbier A, Spencer J, Ypinazar V : How can experience in clinical and community settings contribute to early medical education? A BEME systematic review. Med Teach 28 : 3-18, 2006
4. Tani K, Iwasaki T, Kawaminami S, Yuasa S, Saijo A : Evaluation of primary care practice in the University of Tokushima. J Med Invest $56: 81-87,2009$

5. Okayama M, Kajii E : Does community-based education increase students' motivation to practice community health care? -a cross sectional study. BMC Med Educ 11 : 19-24, 2011

6. Jablonover RS, Blackman DJ, Bass EB, Morrison G, Goroll AH : Evaluation of a national curriculum reform effort for the medical core clerkship. J Gen Intern Med 15 : 48491, 2000

7. Howe A: Twelve tips for community-based medical education. Medical Teacher 24 : 9-12, 2002

8. Verby JE, Newell JP, Andresen SA, Sentko $\mathrm{WM}$ : Changing the medical school curriculum to improve patient access to primary care. JAMA 266 : 110-113, 1991

9. Grayson MS, Klein M, Franke KB : Impact of a first-year primary care experience on residency choice. J Gen Intern Med 16 : 860-863, 2001

10. Critchley J, DeWitt DE, Khan MA, Liaw ST : A required rural health module increase students' interest in rural health careers. Rural Remote Health 7 : 688-693, 2007

11. Griffith $\mathrm{CH}$ third-, Wilson JF : The loss of student idealism in the third-year clinical clearkships. Eval Health Prof 24 : 61-71,2001

12. Ali A : Community-oriented medical education and clinical training : comparison by medical students in hospitals. J Coll Physicians Surg Pak22 : 622-628, 2012

13. Cabinet Office, Government of Japan [http : // www8.cao.go.jp/kourei/whitepaper/w-2013/ zenbun/s1_1_1_02.html]

14. Economic Co-operation and Development (OECD) Health data 2008. Kyodo News Service.

15. Coordinating Council on revising the model core curriculum. Model core curriculum in medical education, the guideline for the educational programme; revised edition in 2007.

16. Inoue $\mathrm{K}$, Hirayama $\mathrm{Y}$, Igarashi $\mathrm{M}$ : A medical school for rural areas. Med Educ 31 : 430-434, 1997 